\title{
Characteristics and Risk Management of School Sports Injury Accidents in Yunnan Province
}

\author{
Shunbi Mu ${ }^{1, *}$ Aihua Zhang ${ }^{1}$ \\ ${ }^{1}$ College of Sports, Yunnan Normal University, Kunming, Yunnan, China \\ *Corresponding author. Email: zhangaihua_521@163.com
}

\begin{abstract}
The improvement of school sports laws and regulations is of great significance to the fair education of school sports and the realization of students' sports rights. The methods of literature research, logical analysis and mathematical statistics were employed in this paper to analyse 22 legal judgments on "Injury Accidents in School Sports in Yunnan Province" downloaded from "China Judgments Online". The results were as follows: (1) Fracture (81.8\%) was the main school sports injury accident in Yunnan Province; (2) The injuries were upper limbs, head, lower limbs and trunk in order. Compound injuries were generally serious, with $50 \%$ of the cases reaching "level 10" disability, and the most serious was "level 5" disability, with 1 death; (3) The victims of school sports injury accidents in Yunnan Province were mainly aged 8-17, and the majority were primary school students, followed by junior and senior high school students; (4) The number of injured boys was less than that of girls; (5) Injuries often occur in physical education classes, relatively unorganized sports activities, sports activities in mixed venues, or when students play; (6) Gymnastics, track and field and basketball are the main events, and other events are relatively few; (7) The school is the main body of responsibility for sports injury accidents. Five suggestions were put forward: (1) To establish and improve the relevant laws and systems for the development of school physical education; (2) To improve the school sports safety inspection, supervision and management system; (3) To strengthen the legal awareness of sports practitioners, enhance the legal literacy and safety awareness of physical education teachers and students; (4) To design and improve the "insurance" system; (5) To increase responsibility education for the projects and field staff with high probability of sports injury accidents in schools to prevent accidents.
\end{abstract}

Keywords: Yunnan Province, Sports injury accident, Legal responsibility, Risk management.

\section{INTRODUCTION}

The rapid development of the times and the perfection of the legal system have promoted the legislation and judicial practice of school physical education in China. This is of great significance to the realization of the fair education and sports rights of school sports, the effective promotion of school sports activities, and the guarantee of campus safety. It also contributes much to the solution of many problems in the development of school sports practice.

\section{RESEARCH OBJECT AND METHOD}

\subsection{Research Object}

The 22 judgments of "school sports injury accidents in Yunnan Province" selected from "China Judgments Online" were taken as the research object.

\subsection{Research Method}

\subsubsection{Literature Data Method}

Among the papers that are closely related to this paper on CNKI, 43 papers have been studied in depth, laying a theoretical foundation for the writing. 


\subsubsection{Logical Analysis}

The legal rule itself is a judgment and proposition composed of various concepts and a rigorous logical structure. It is composed of numerous legal systems, which must have strict logical consistency to convince the parties and the public to believe in the justice of law. Therefore, logical analysis runs through each case and analysis link in this paper in order to get more objective and notarized analysis results.

\subsubsection{Mathematical Statistics}

First, the 22 "sports injury accidents in school in Yunnan Province" judgements selected from "China Judgments Online" are classified according to the court of judgment, the cause of the case, the sports event where the sports injury occurred, the venue, time, and the defendant. Statistics, data analysis is carried out through SPSS25.0.

\section{ANALYSIS OF THE RESULTS OF SCHOOL SPORTS INJURY ACCIDENTS IN YUNNAN PROVINCE}

\subsection{Age and Learning Period of Sports Injury Accident}

"Table 1" shows that the age of injured people in sports injury accidents is between 8 and 17 years old, and the age of 17 years old accounts for the largest proportion, up to $22.7 \%$. However, there are no less than 3 cases between 13 and 17 years old, accounting for at least $13.6 \%$. It can be seen that sports injury accidents in schools in Yunnan Province in this age group are a "high incidence area".

Table 1. Age of injured person $(n=22)$

\begin{tabular}{lllllllllll}
\hline Victim's age (years) & 8 & 9 & 10 & 12 & 13 & 14 & 16 & 17 & 89 & total \\
\hline Frequency (person) & 1 & 3 & 2 & 1 & 3 & 3 & 3 & 5 & 1 & 22 \\
Percentage (\%) & 4.5 & 13.6 & 9.1 & 4.5 & 13.6 & 13.6 & 13.6 & 22.7 & 4.5 & 100 \\
\hline
\end{tabular}

Table 2. Identity of the injured person $(n=22)$

\begin{tabular}{|c|c|c|c|c|c|}
\hline \multirow[b]{2}{*}{ injured person } & \multicolumn{3}{|c|}{ Elementary schoolJunior high schoolHigh } & \multicolumn{2}{|l|}{ school } \\
\hline & student & student & student & Passersby & total \\
\hline Frequency (person) & 10 & 9 & 2 & 1 & 22 \\
\hline Percentage (\%) & 45.5 & 40.9 & 9.1 & 4.5 & 100 \\
\hline
\end{tabular}

"Table 2" shows that primary school students $(45.5 \%)$ and junior middle school students $(40.9 \%)$ are the main victims. In combination with the comparison of "Table I" and "Table II" with similar national studies, Li Chuntao from Sichuan Normal University analyzed 145 referees and "physical education injury accidents of students aged 8-16" in master's thesis. It is concluded that the number of injured students aged 11-14 is the most, accounting for $62.1 \%$, and the number of injured students aged 14-16 is gradually decreasing, among which the number of infringed students aged 11 is the most, accounting for $17.8 \%$.

However, its conclusion is not consistent with the conclusion of this paper, which may be due to the sample size or schools and sports venues, etc., which needs to be further confirmed by follow-up studies. 


\subsection{The Gender of Sports Injury Accidents}

"Figure 1" shows that sports injury accidents on campus mainly happen to male students, while the proportion of female students is small.

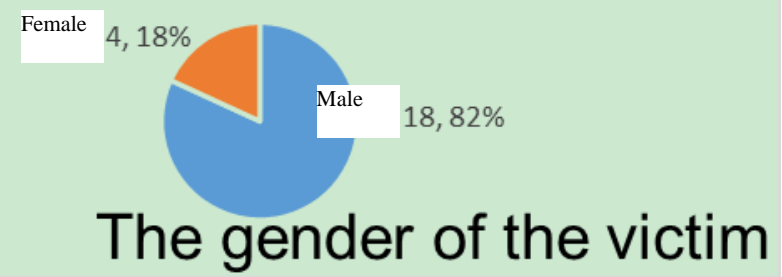

Figure 1 The gender of victim.

\subsection{The Items and Causes of Sports Injury Accidents}

According to "Table 3", among the 22 referees, sports injury accidents are mainly happened in gymnastics, track and field and basketball.

Table 3 . The items of sports injury accidents $(n=22)$

\begin{tabular}{lllllll}
\hline item & gymnastics & track and field & basketball & other & skate & total \\
\hline Frequency (person) & 7 & 6 & 4 & 4 & 1 & 22 \\
Percentage (\%) & 31.8 & 27.3 & 18.2 & 18.2 & 4.5 & 100 \\
\hline
\end{tabular}

a Note: the division of the items is bound by the content, for example, the "ladder" of the playground or the track and field is classified into the "gymnastics" events because of the similar climbing events.

\subsection{Location of Sports Injury Accident}

As shown in "Table 4", the chi-square test after the statistics of the data in the 22 judgment documents showed that the chi-square value was

Table 4. Locations of sports injury accidents $(n=22)$

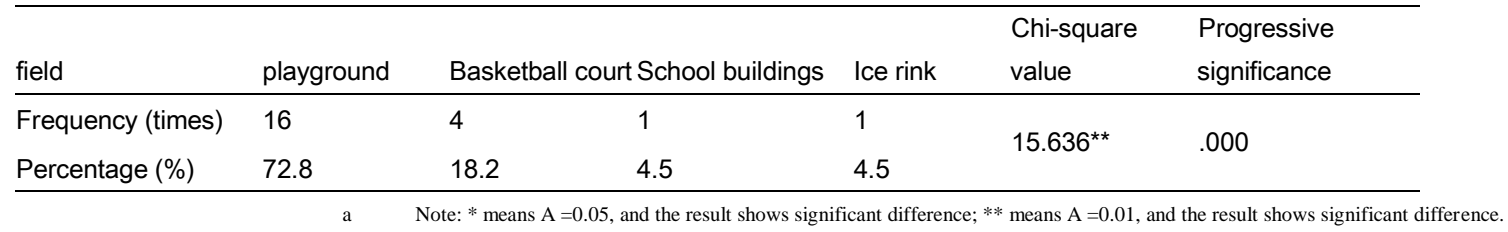

In addition, according to "Responsibility Dispute Case between Zhao Bangyou, Qin Shunling et al and Educational Institution of Baihetan Middle School in Qiaojia County (2017) Yun 0622 Minchu No. 1515", due to the safety problem of the school basketball rack, a student surnamed Zhao was "jumping and hanging the basketball net, the main pole of the basketball rack suddenly broke from the base, and the basketball rack hit Zhao, causing his head injury, and
15.636, $\mathrm{P}=0.000<\mathrm{a}=0.05$, and the difference was significant and statistically significant. Sports injury accidents occur mainly in the playground, followed by the basketball court, so "playground" is the key place to prevent sports injury accidents. he died after rescue". This is worthy of the high attention of schools. 


\subsection{The Time when Sports Injury Accidents Occur}

"Table 5" shows that the chi-square value of the judgment documents of 22 school sports injury accidents in Yunnan Province is 15.636, $\mathrm{P}=0.000<\mathrm{a}=0.05$, and the difference is significant and statistically significant. It can be seen that sports injury accidents mostly occur in the physical education class, and then the big break and after school. Therefore, the physical education class and the big break are the key areas to prevent sports injury accidents.

Table 5. Time of sports injury accidents $(n=22)$

\begin{tabular}{lllllll}
\hline & Physical & & & & Chi-square & Progressive \\
Time of injury & Education & Big break & After school & After class time value & significance \\
Frequency (times) & 14 & 4 & 3 & 1 & $18.364^{\star *}$ & .000 \\
Percentage $(\%)$ & 63.6 & 18.2 & 13.6 & 4.5 & \\
\hline \multicolumn{7}{r}{ a Note: * means $\mathrm{A}=0.05$, and the result shows significant difference; $* *$ means $\mathrm{A}=0.01$, and the result shows significant difference. }
\end{tabular}

Table 6 . Injured parts of sports injury accidents $(n=$ more than 22 items)

\begin{tabular}{lllll}
\hline Injured part & head & Upper limb & Lower limbs & trunk \\
\hline Frequency (person) & 6 & 10 & 6 & 4 \\
Percentage (\%) & 27.2 & 45.5 & 27.2 & 18.2 \\
\hline
\end{tabular}

Table 7. Specific locations of injuries and fractures in sports injury accidents ( $n=$ more than 22 items)

\begin{tabular}{|c|c|c|c|}
\hline sequence & Case number & fracture & Specific parts of injury in sports injury accidents \\
\hline 1 & (2014) Panfa Minyi Chuzi No. 442 & Yes & Fracture of radius in left arm \\
\hline 2 & (2014) Zhenmin Chuzi No. 392 & Yes & Left elbow fracture \\
\hline 3 & (2015) Mu Min Chu Zi No. 781 & Yes & $\mathrm{n}$ avulsion fracture of the small head of the left humerus \\
\hline 4 & (2015) Chu Min Chu Zi No. 3058 & No & splenectomy \\
\hline 5 & (2016) Yun 0129 Min Chu No. 437 & Yes & Fracture of right inferior radius \\
\hline 6 & (2016) Yun 0628 Min Chu No. 25 & Yes & Left humerus fracture \\
\hline 7 & (2016) Yun 0623 Min Chu No. 2063 & Yes & Bilateral linear fracture of temporal bone \\
\hline 8 & (2017) Yun 0181 Min Chu No.856 & Yes & Fracture of right femoral shaft \\
\hline 9 & (2017) Yun 2329 Min Chu No.190 & Yes & Fracture of the upper middle part of the left femur \\
\hline 10 & (2017) Yun 2504 Min Chu No.659 & Yes & $\begin{array}{l}\text { 1. Closed fracture of left femoral neck; } 2 \text {. Traumatic hemorrhagic anemia; } 3 \text {. } \\
\text { Arrhythmia: ventricular, borderline premature beats; } 4 . \text { Severe } \\
\text { Osteoporosis. }\end{array}$ \\
\hline 11 & (2017) Yun 0627 Min Chu No. 1209 & Yes & Occipital fracture, left foot injury \\
\hline 12 & (2017) Yun 0622 Min Chu No. 1515 & No & Severe head bleeding \\
\hline 13 & (2017) Yun 0103 Min Chu No. 6550 & Yes & Left humerus fracture \\
\hline 14 & (2017) Yun 0627 Min Chu No. 3414 & Yes & Fracture of the coronoid process of the left ulna \\
\hline 15 & (2017) Yun 0602 Min Chu No. 991 & Yes & Spiral fracture of the middle and lower left tibia \\
\hline 16 & (2018) Yun 2924 Min Chu No. 198 & Yes & Fracture of right humerus \\
\hline 17 & (2018) Yun 2501 Min Chu No. 1228 & No & Head injury \\
\hline 18 & (2018) Yun 0825 Min Chu No. 634 & Yes & Left humerus fracture \\
\hline 19 & (2019) Yun 2901 Min Chu No. 204 & Yes & Comminuted fracture of the right proximal femur \\
\hline 20 & (2019) Yun 0602 Min Chu No. 1338 & No & Left testicular exploratory resection + Removal of scrotal hematoma \\
\hline 21 & (2019) Yun 0381 Min Chu No. 4838 & Yes & $\begin{array}{l}\text { 1. Brain contusion and laceration in right frontotemporal lobe; } 2 \text {. Acute } \\
\text { subdural thin hematoma at the top of right forehead; } 3 \text {. Hemorrhage in the } \\
\text { longitudinal fissure; } 4 \text {. fracture of skull; } 5 \text {. Separation of the sagittal suture } \\
\text { and the left herringbone suture; } 6 \text {. fracture of skull base; } 7 \text {. Chest and back } \\
\text { contusion; } 8 \text {. hematoma of scalp; } 9 \text {. Scalp contusion; } 10 \text {. Right ethmoid } \\
\text { sinus and frontal sinusitis. }\end{array}$ \\
\hline 22 & (2020) Yun 0323 Min Chu No. 321 & Yes & Fracture of left humerus \\
\hline
\end{tabular}




\subsection{Injured Parts and Specific Locations of Sports Injury Accidents}

"Table 6" shows that in the 22 referees, upper limbs accounted for $38.5 \%$ of the injured parts in sports injury accidents, followed by the head, lower limbs and trunk. In some cases, there were more than one injured parts.

"Table 7" showed that 18 of the 22 cases $(81.8 \%)$ had fractures at different sites. Three cases (No. 10, 11 and 21) were complex injuries. The other four cases (No. 21) had multiple fractures, and the other four cases were splenectomy, head injury, massive hemorrhage of the head, left testicular exploratory resection and removal of scrotal hematoma. It can be seen that "fracture" is a typical feature of sports injury accidents in schools in Yunnan Province.

\subsection{The Level of Disability that Occurs in Sports Injury Accidents}

"Table 8" shows that in sports injury accidents in Yunnan Province, 50\% of the cases reached "Level 10 " disability, the most serious disability reached "Level 5" disability, and there was 1 death case.

Table 8. Disability level of injured persons in sports injury accidents $(n=22)$

\begin{tabular}{llllllll}
\hline Disability level & Level 5 & Level 7 & Level 8 & Level 9 & Level 10 & No level & total \\
\hline Frequency (person) & 2 & 2 & 1 & 3 & 11 & 3 & 22 \\
Percentage (\%) & 9.1 & 9.1 & 4.5 & 13.6 & 50.0 & 13.6 & 100 \\
\hline
\end{tabular}

\subsection{The Situation of the Defendant in the Sports Injury Accident and the Compensation}

"Table 9" shows that among the 22 sports injury accidents in Yunnan Province, 21 cases (accounting for $95.5 \%$ ) were accused by schools. Next came parents at 31.8 percent, followed by teachers, insurance companies and operators at 4.5 percent each. In 95.5 percent of the cases, the schools paid compensation, ranging from 100 percent to 10

Table 9. Defendants in sports injury accidents $(n=$ more than 22 items)

\begin{tabular}{lllllc}
\hline Indemnifier & school & Parent & teacher & \multicolumn{2}{c}{ Insurance companyOperators } \\
\hline Frequency (person) & 21 & 7 & 1 & 1 & 1 \\
Percentage (\%) & $95.5 \%$ & $31.8 \%$ & $4.5 \%$ & $4.5 \%$ & $4.5 \%$ \\
\hline
\end{tabular}

\subsection{The Main Penalty Basis of Sports Injury Accident}

"Table 10" shows that in the legal judgment of sports injury accidents in Yunnan Province, the main

Table 10. The main penalty principles used in the judging process of sports injury accidents $(n=22)$

\begin{tabular}{lllll}
\hline Injured part & Fault principle & The principle of fairness & Assumption of risk & total \\
\hline Frequency (person) & 18 & 2 & 2 & 22 \\
Percentage (\%) & 81.8 & 9.1 & 9.1 & 100 \\
\hline
\end{tabular}

Only 2 cases simply use the "assumption of risk", which may have something to do with the time when the principle was formally introduced into the legislative process. the "fairness principle".

percent, according to the adjudication documents. $63.6 \%$ of the plaintiffs were liable, and $59.1 \%$ of the defendants were classmates. It may also be due to these reasons that the school is the main body of responsibility for sports injury accidents in Yunnan Province. Of course, this may also be related to the division of legal liability and humanitarianism in China, which needs to expand the research sample for further demonstration. basis is still the "fault principle", and the second is the "fairness principle". 


\subsection{The Main Causes of Sports Injury Accidents}

Multiple dimensions of 22 sports injury accidents in Yunnan Province, such as time period, evidence provided by the plaintiff and the defendant in the court in legal documents, and fact finding, show that although the accidents mostly occur in physical education class (as shown in Table 5), most of them occur in the gap of unified teaching organization, unorganized sports activities, mixed sports venues, and sports activities. The main causes of campus injury accidents are the lack of safety awareness of students, the inability to control their own dangerous behaviours and the existence of safety hazards in the school sports environment.

\section{CHARACTERISTICS OF SCHOOL SPORTS INJURIES IN YUNNAN PROVINCE}

- Among the 22 judgment documents of sports injury accidents in Yunnan Province, the injured people are mainly primary school students and junior high school students, and the injured people are mainly aged between 8 and 17 .

- Most of the victims of sports injury accidents in Yunnan Province are male, but few female, which is basically consistent with the conclusion of similar research in the country.

- Gymnastics, track and field and basketball are the main sports injury accidents in Yunnan Province, while other sports are relatively few. Injury accidents mainly occur on the playground and in physical education class, and mostly occur in the relatively unorganized sports gap in physical education class, sports activities carried out in mixed venues, or when students play.

- Fracture $(81.8 \%)$ is the main school sports injury accident in Yunnan Province. The proportion of injured parts was upper limbs, head, lower limbs and trunk in descending order. Compound injuries are generally serious, with $50 \%$ of the cases reaching "level 10" disability, and the most serious being "level 5" disability, with 1 death.

- The legal judgment documents of sports injury accidents in Yunnan Province show that the main basis of the legal judgment is still the "fault principle", and the proportion of compensation is considered according to the degree of liability. In $95.5 \%$ of the cases, the defendants are schools, and they need to compensate. Schools are the main body of responsibility in sports injury accidents on campus, which is consistent with similar research conclusions across the country.

- The identity of the plaintiff and the defendant and the cause of injury show that students' lack of safety awareness, inability to control their dangerous behaviors, and the existence of safety hazards in the school sports activity environment are to blame for school sports injury accidents.

\section{RISK MANAGEMENT STRATEGY OF SCHOOL SPORTS INJURY ACCIDENT}

- Establishing and improving the relevant laws and systems for the development of school physical education, clarify the division of responsibilities and detailed rules for compensation, and solving the problems such as large degree of freedom in compensation for school sports injury accidents.

- Improving the school sports safety inspection, supervision and management system, and solving the problems such as the "subject of responsibility" for school sports injury accidents in Yunnan Province, the heavy burden of school compensation, and the limitation of carrying out sports activities.

- Strengthening the legal awareness of sports practitioners, improving the legal literacy and safety awareness of physical education teachers and students, so as to restrain the dangerous behaviors of irresponsible teachers and students, regulate the normal order of physical education teaching and form good sports behaviors.

- Designing and improving the "insurance" system to solve the problems of excessive pressure on school sports activities and humanitarian compensation.

- Strengthening the responsibility education of the events and site staff that are prone to sports injury accidents in school to prevent the occurrence of sports injury accidents in school.

\section{CONCLUSION}

In summary, the 22 legal judgments of "Injury Accidents in School Sports in Yunnan Province" downloaded from "China Judgments Online" indicate that the main characteristics of injury accidents in school sports in Yunnan Province are as follows. Injury accidents often occur in the gap of physical 
education, or when students play. The injuries mainly occurred in gymnastics, track and field and basketball events, and the majority of the injuries were male. Injuries mainly occurred in the upper extremities, head, lower extremities and trunk. Fractures are common in compound injuries. Half were "level 10 disabled". In case of risk management, attention should be paid to the establishment and improvement of relevant laws and systems and safety management systems for the development of school physical education. The legal consciousness and safety consciousness of sports practitioners should be strengthened. The "insurance" system should be perfected, and the responsibility education of school sports staff should be enhanced to prevent the occurrence of school sports injury accidents.

\section{AUTHORS' CONTRIBUTIONS}

Shunbi $\mathrm{Mu}$ is responsible for the arrangement, statistics and analysis of each item in the article and the final writing of the manuscript. Aihua Zhang is responsible for the search, collection and screening of school sports injury accidents in Yunnan Province.

\section{REFERENCES}

[1] Li Chuntao. Characteristics of 8-16 Years Old Students' Injury Accidents in Physical Education Classes and Preventive Measures Analysis: Analysis Based on Judgement Documents [D]. Sichuan Normal University, 2020. (in Chinese)

[2] Zhang Yunbo. Study on Characteristics Analysis and Preventive Measures of Student Sports Injury Accidents: Analysis Based on 835 Civil Judgements [D]. Capital University of Physical Education and Sports, 2020. (in Chinese)

[3] Liu Xintao. Research on Handling and Risk Prevention of Football Injury Accidents in Primary and Middle School Campuses in Hunan Province [D]. Hunan Normal University, 2020. (in Chinese)

[4] Zhang Zhuo. Analysis of the Causes of Sports Injury Accidents in Rural Primary and Secondary Schools and the Countermeasures: Taking the Rural School in Dalian as an Example [D]. Liaoning Normal University, 2020. (in Chinese)

[5] Zhou Ying. A Brief Talk on Strategies to Effectively Avoid Primary School Sports Injury
Accidents [J]. Primary School Students (Late Period), 2020(09): 30. (in Chinese)

[6] Li Xianyan. Different Principles of Liability for School Sports Injury Accidents in Local Regulations of China: With Civil Code of Tort Liability as Background [J]. Journal of Shandong Sport University, 2020, 36(05): 52 58. (in Chinese)

[7] Lian Xiaogang, Shi Yan. Research on School Sports Insurance Model in China [J]. Journal of Xi'an Physical Education University, 2020, 37(03): 304-312. (in Chinese)

[8] Xu Wenqiang. Research on the Prevention and Control of Sports Injury Risk in the Compulsory Education Stage [J]. Sport \& Style, 2020(04): 286. (in Chinese)

[9] https://wenshu.court.gov.cn/China Judgments Online. 